\title{
Novel synthetic analogues of Fluoxetine as potent and selective anti-TB agents
}

\author{
M. Murali Krishna Kumar*, K. Madhavi, T. Mohan, K. Purna Nagasree, G.P.V. Sangeeta \\ Pharmaceutical Chemistry Research Labs, College of Pharmaceutical Sciences, Andhra University, Visakhapatnam - 530003 , India.
}

\section{ARTICLE INFO \\ Article history: \\ Received on: 12/03/2018 \\ Accepted on: 27/06/2018 \\ Available online: 31/08/2018}

\section{Key words:}

Acetophenone mannich

bases, fluoxetine,

antitubercular activity, drug

repurposing.

\begin{abstract}
We have recently identified potent anti-TB activity in several CNS drugs. Most prominently, the phenothiazine antipsychotics (Thioridazine-MIC $3.125 \mu \mathrm{g} / \mathrm{mL}$ ) and anti-depressant drugs (sertraline-MIC $1.6 \mu \mathrm{g} / \mathrm{mL}$ ) have shown anti-TB activity against Mycobacterium tuberculosis H37Rv. In continuation, we have synthesized a series of 1-(3-aryloxy-3-phenylpropyl) amine analogues of fluoxetine to optimize its anti-TB activity. Identities of the synthesized compounds were confirmed by FTIR, ${ }^{1} \mathrm{H}$ NMR and mass spectral analysis. They were tested for in vitro antitubercular activity by MABA Assay. To determine selective TB activity, they were also tested for antimicrobial activity. Among the synthesized compounds, 1-(3-(4-fluorophenoxy)-3-phenylpropyl) piperidine (AM3e) has shown highest anti-TB activity (MIC $1.6 \mu \mathrm{g} / \mathrm{mL}$ ) against MtbH37Rv and is free from antibacterial/antifungal activity (MIC $>100 \mu \mathrm{g} / \mathrm{mL})$.
\end{abstract}

\section{INTRODUCTION}

As per WHO report released recently, drug resistance has been noted for almost every antibiotic in use today. The list includes aminoglycosides, peptides, $\beta$-lactams, sulfonamides, nitroimidazoles, quinolones, tetracyclines, chloramphenicol and macrolides (WHO report, 2017). It is becoming a major threat to concern for the development of modern medicine (Willyard et al., 2017). Mycobacterium tuberculosis (Mtb) is the causative agent for one of the deadliest infectious diseases, tuberculosis. It is known for its "signature" lipid-rich cell wall, which offers a formidable barrier to most of the antibiotics. Further, it is also known to develop drug resistance to a multitude of chemotherapeutic agents. In 2016-17 alone, a total of 600000 cases with resistance to rifampicin (RRTB) were reported, of which 490000 were with multidrug resistance. Drug resistance in Mtb arises predominantly from a change of intracellular target protein/enzyme (WHO report,

${ }^{*}$ Corresponding Author

M. Murali Krishna Kumar, Pharmaceutical Chemistry Research Labs, College of Pharmaceutical Sciences, Andhra University, Visakhapatnam -530003.E-mail:drmmkau@gmail.com
2017; Juan Carlos et al., 2014).

Hence, development of a novel agent targeting an essential mycobacterial biochemical pathway only can offer a dependable drug molecule. In this regard, search for structurally diverse anti- $\mathrm{Tb}$ agents, especially those with a novel mechanism of action has received a great deal of attention in the recent past. Repurposing of FDA approved "non-antibiotic" drugs has also aroused immense interest in anti-TB drug researchers, as it presumed to inflict less financial/clinical trial burden. Several CNS agents including antipsychotics (viz. phenothiazines) and antidepressant agents (viz. fluothe xetine) were reported to have potent antimicrobial activity against bacteria including Mtb. (Marta Martins et al., 2008; Lass-Florl et al., 2001; Kristiansen et al., 2007; Murali Krishna Kumar et al., 2015; Munoz-Bellido et al., 2000). In view of its potential antimicrobial properties, fluoxetine analogues have been explored for antifungal activity against Candida sp. (Romano Silvestri et al., 2004). These reports and our personal interest in anti-TB drug discovery (Harian Babu Bolikala et al., 2017; Murali Krishna Kumar et al., 2015), has induced us to do ligand optimization studies on fluoxetine by altering substitutions on aryloxy group and replacing methyl amino group with piperidine/piperazine. 


\section{MATERIALS AND METHODS}

\section{Instruments and reagents}

Melting points (m.p.) were recorded on Digimelt (Stanford Research Systems, USA) Automatic melting point apparatus by the one-end-open capillary method and are uncorrected. Biotage Initiator was used for microwave synthesis. The reaction was conducted at $100^{\circ} \mathrm{C}(40 \mathrm{~W})$ with absorption level high and fixed holding time switched $\mathrm{ON}$, in a crimped $10 \mathrm{ml}$ microwave reaction vessel. Crimped microwave vial. IR spectra were recorded on a Bruker-Alpha FTIR spectrometer using $\mathrm{KBr}$ pellet method. NMR spectra were recorded on a Bruker Avance II 400 NMR spectrometer in a proper deuterated solvent using TMS as an internal standard. Mass spectra were recorded on Agilent QQQ LCMS-6410 mass spectrometer. Pre-coated TLC plates were used for monitoring synthetic reactions and also to find out uniformity of synthesized compounds. All laboratory grade reagents were procured and used as received.

\section{Synthesis of compounds AM1-6 (Ali S et al., 2002)}

Acetophenone mannich bases were obtained by a solid phase microwave synthetic method (Scheme 1). Acetophenone (1 $\mathrm{mmol})$, paraformaldehyde $(1 \mathrm{mmol})$ and appropriate amine $(1.1$ $\mathrm{mmol}$ ) were thoroughly mixed and adsorbed on acidic alumina (2 grams) in a china dish. This reaction mixture was then transferred to a $10 \mathrm{ml}$ reaction vial and crimped. It was then subjected to microwave irradiation $\left(100^{\circ} \mathrm{C}, 40\right.$ Watts $)$ using Biotage Initiator for 5 minutes. Upon completion of the reaction, as indicated by TLC, the product was obtained via extracting the reaction mixture with ethyl acetate. The products AM2 to AM6 were obtained in sufficiently pure form after usual work-up and washed with hexanes. AM1 was purified by column chromatography using eluent ethyl acetate: hexane (9:1).

\section{3-(Diethylamino)-1-phenylpropan-1-one (AM1)}

Colorless oil, Yield: $85 \%$. IR (KBr) $v_{\max } \mathrm{cm}^{-1}: 1281$, 1602, 1675, 2815, 3072. ${ }^{1} \mathrm{H}$ NMR (400 MHz, $\left.\mathrm{CDCl}_{3}\right): 1.09$ (t, 6H, $J=7 \mathrm{~Hz}), 2.45(\mathrm{~m}, 4 \mathrm{H}, J=7 \mathrm{~Hz}), 2.65(\mathrm{t}, 2 \mathrm{H}, J=6 \mathrm{~Hz}), 2.98(\mathrm{t}$, $2 \mathrm{H}, J=6 \mathrm{~Hz}), 7.31$ (dd. $2 \mathrm{H}, J=8 \mathrm{~Hz}), 7.45$ (m, 1H), 7.99 (d, 2H $J=8.2 \mathrm{~Hz})$. ESIMS $(\mathrm{M}+\mathrm{H})^{+} \mathrm{m} / \mathrm{z}: 206$.

\section{3-Morpholino-1-phenylpropan-1-one (AM2)}

Colorless solid, Yield $=78 \%, \mathrm{mp} 177-179^{\circ} \mathrm{C}$. IR $(\mathrm{KBr})$ $v_{\max } \mathrm{cm}^{-1}: 1194,1285,1585,1680,2969,3082 .{ }^{1} \mathrm{H}$ NMR $(400$ $\left.\mathrm{MHz}, \mathrm{CDCl}_{3}\right): 2.42(\mathrm{~m}, 4 \mathrm{H}), 2.79(\mathrm{t}, 2 \mathrm{H}, J=4 \mathrm{~Hz}), 3.12(\mathrm{t}, 2 \mathrm{H}, J$ $=4 \mathrm{~Hz}), 3.69(\mathrm{~m}, 4 \mathrm{H}), 7.35(\mathrm{~m}, 2 \mathrm{H}), 7.45(\mathrm{~m}, 1 \mathrm{H}), 7.88(\mathrm{~m}, 2 \mathrm{H})$. ESIMS $(\mathrm{M}+\mathrm{H})^{+} m / z: 220$.

\section{1-Phenyl-3-(piperidin-1-yl)propan-1-one (AM3)}

White colored Semi solid,Yield $=92 \% . \mathrm{IR}(\mathrm{KBr}) v_{\max } \mathrm{cm}^{-1}$ : 1282, 1601, 1670, 2913, 3079. ${ }^{1} \mathrm{H}$ NMR (400 MHz, $\left.\mathrm{CDCl}_{3}\right): 1.61(\mathrm{~m}$, $6 \mathrm{H}), 2.55(\mathrm{t}, 4 \mathrm{H}, J=4 \mathrm{~Hz}), 2.89(\mathrm{t}, 2 \mathrm{H}, J=6 \mathrm{~Hz}), 2.96(\mathrm{t}, 2 \mathrm{H}, J=6 \mathrm{~Hz})$, $7.35(\mathrm{~m}, 2 \mathrm{H}), 7.42(\mathrm{~m}, 1 \mathrm{H}), 7.84(\mathrm{~m}, 2 \mathrm{H})$. ESIMS (M+H) ${ }^{+} \mathrm{m} / z: 218$.

\section{1-Phenyl-3-(4-phenylpiperazin-1-yl)propan-1-one (AM4)}

Colorless solid, Yield $=90,116-117^{\circ} \mathrm{C}$. IR $(\mathrm{KBr}) v_{\max }$ $\mathrm{cm}^{-1}: 1258,1595,1682,2962,3056 .{ }^{1} \mathrm{H} \mathrm{NMR}\left(400 \mathrm{MHz}, \mathrm{CDCl}_{3}\right)$ : $2.69(\mathrm{~m}, 4 \mathrm{H}), 2.92(\mathrm{t}, 2 \mathrm{H}, J=5.8 \mathrm{~Hz}), 3.01(\mathrm{t}, 2 \mathrm{H}, J=5.8 \mathrm{~Hz})$, $3.29(\mathrm{~m}, 4 \mathrm{H}), 6.83-6.95(\mathrm{~m}, 3 \mathrm{H}), 7.13(\mathrm{~m}, 2 \mathrm{H}), 7.42(\mathrm{~m}, 3 \mathrm{H}), 7.95$ $(\mathrm{dd}, 2 \mathrm{H}, J=7.8 \mathrm{~Hz})$. ESIMS $(\mathrm{M}+\mathrm{H})^{+} \mathrm{m} / z: 295$.

3-(4-Benzylpiperazin-1-yl)-1-phenylpropan-1-one (AM5)

Colorless solid, Yield $=90,136-139^{\circ} \mathrm{C} . \mathrm{IR}(\mathrm{KBr}) v_{\max }$ $\mathrm{cm}^{-1}:$ 1296, 1595, 1643, 2962, 3093. ${ }^{1} \mathrm{H}$ NMR (400 MHz, $\mathrm{CDCl}_{3}$ ): $2.29(\mathrm{~m}, 4 \mathrm{H}), 2.54(\mathrm{~m}, 4 \mathrm{H}), 2.61(\mathrm{t}, 2 \mathrm{H}, J=5.7 \mathrm{~Hz}), 2.92(\mathrm{t}, 2 \mathrm{H}$, $J=5.7 \mathrm{~Hz}), 3.52(\mathrm{~s}, 2 \mathrm{H}) 7.21-7.55(\mathrm{~m}, 8 \mathrm{H}), 7.96(\mathrm{~d}, 2 \mathrm{H}, J=7.9$ $\mathrm{Hz})$. ESIMS (M+H) $m / z: 309$.

3-(4-Benzylpiperidin-1-yl)-1-phenylpropan-1-one (AM6)

Colorless solid, Yield $=88,128-129^{\circ} \mathrm{C}$. IR $(\mathrm{KBr})$ $V_{\max } \mathrm{cm}^{-1}: 1281,1597,1679,2846,3082 .{ }^{1} \mathrm{H}$ NMR $(400 \mathrm{MHz}$, $\left.\mathrm{CDCl}_{3}\right): 1.08(\mathrm{~m}, 2 \mathrm{H}), 1.41(\mathrm{~m}, 2 \mathrm{H}), 1.61(\mathrm{~m}, 1 \mathrm{H}), 1.87(\mathrm{t}, 2 \mathrm{H}$, $J=4 \mathrm{~Hz}), 2.46(\mathrm{~d}, 2 \mathrm{H}, J=4.8 \mathrm{~Hz}), 2.83(\mathrm{t}, 2 \mathrm{H}, J=4.6 \mathrm{~Hz})$, $2.72(\mathrm{t}, 2 \mathrm{H}, J=4 \mathrm{~Hz}), 7.08(\mathrm{~d}, 2 \mathrm{H}, J=7.8 \mathrm{~Hz}), 7.17(\mathrm{dd}, 1 \mathrm{H}$, $J=7 \mathrm{~Hz}), 7.24(\mathrm{~d}, 2 \mathrm{H}, J=7.4 \mathrm{~Hz}), 7.44(\mathrm{dd}, 2 \mathrm{H}, J=7.8 \mathrm{~Hz})$, $7.54(\mathrm{dd}, 1 \mathrm{H}, J=7.6 \mathrm{~Hz}), 7.93(\mathrm{~d}, 2 \mathrm{H}, J=7.4 \mathrm{~Hz})$. ESIMS $(\mathrm{M}+\mathrm{H})^{+} \mathrm{m} / z: 308$.

Synthesis of compounds AM1a-6a: Sodium borohydride $(30 \mathrm{mmol})$ was added in portions to a stirred and cooled solution of Mannich bases (AM1-AM6) (10 mmol) in methanol $(25 \mathrm{~mL})$ over a period of $30 \mathrm{~min}$. The reaction mixture was further stirred at room temperature for $4 \mathrm{~h}$. Methanol was distilled under reduced pressure. The residue was triturated with water $(25 \mathrm{~mL})$ and extracted 3 times with dichloromethane $(15$ $\mathrm{mL}$ ). The combined organic layer was dried over sodium sulfate and concentrated to give the hydroxyl compounds AM1a-AM6a in $>90 \%$ yield as colorless oils.

\section{3-(Diethylamino)-1-phenylpropan-1-ol (AM1a)}

Yield: 90\%; IR (KBr) $v_{\max } \mathrm{cm}^{-1}: 3259,3081,2924,2827$, $2788,1605,1466,1382,1259,1042 .{ }^{1} \mathrm{H} \mathrm{NMR}\left(400 \mathrm{MHz}, \mathrm{CDCl}_{3}\right)$ : $1.08(\mathrm{t}, 6 \mathrm{H}, J=7.2 \mathrm{~Hz}), 1.78-1.96(\mathrm{~m}, 2 \mathrm{H}), 2.62-2.85(\mathrm{~m}, 6 \mathrm{H})$, 4.95-5.01 (m, 1H), 7.21-7.39 (m, 5H). ESIMS (M+H) ${ }^{+} m / z: 208$.

\section{3-Morpholino-1-phenylpropan-1-ol (AM2a)}

Yield: 92\%; IR (KBr) $v_{\max } \mathrm{cm}^{-1}: 3206,3075,2997,2929$, 2831, 2792, 1501, 1466, 1254, 1219, 1037. ${ }^{1} \mathrm{H}$ NMR $(400 \mathrm{MHz}$, $\left.\mathrm{CDCl}_{3}\right): 1.88(\mathrm{~m}, 2 \mathrm{H}), 2.41-2.46(\mathrm{t}, 2 \mathrm{H}, J=2.8 \mathrm{~Hz}), 2.58-2.65(\mathrm{~m}$, $4 \mathrm{H}), 3.65-3.72(\mathrm{~m}, 4 \mathrm{H}), 4.94(\mathrm{~m}, 1 \mathrm{H}), 7.22-7.36$ (m, 5H). ESIMS $(\mathrm{M}+\mathrm{H})^{+} m / z: 222$.

\section{1-Phenyl-3-(piperidin-1-yl)propan-1-ol (AM3a)}

Yield: 93\%; IR (KBr) $v_{\max } \mathrm{cm}^{-1}: 3260,3078,2906,2815$, 1618, 1512, 1156. ${ }^{1} \mathrm{H}$ NMR (400 $\left.\mathrm{MHz}, \mathrm{CDCl}_{3}\right): 1.35-1.52(\mathrm{~m}$, $6 \mathrm{H}), 1.78(\mathrm{~m}, 2 \mathrm{H}), 2.32-2.35(\mathrm{~m}, 2 \mathrm{H}), 2.45-2.48(\mathrm{~m}, 2 \mathrm{H}), 2.53(\mathrm{~m}$, $2 \mathrm{H}), 4.88(\mathrm{t}, 1 \mathrm{H}, J=5.6 \mathrm{~Hz}), 7.18-7.28(\mathrm{~m}, 5 \mathrm{H}) . \operatorname{ESIMS}(\mathrm{M}+\mathrm{H})^{+}$ $\mathrm{m} / \mathrm{z}: 220$.

\section{1-Phenyl-3-(4-phenylpiperazin-1-yl)propan-1-ol (AM4a)}

Yield: 88\%; IR (KBr) $v_{\text {max }} \mathrm{cm}^{-1}: 3341,3224,3065,2925$, $2835,1614,1523,1465,1242 .{ }^{1} \mathrm{H}$ NMR $\left(400 \mathrm{MHz}, \mathrm{CDCl}_{3}\right)$ : $1.95-$ $1.98(\mathrm{~m}, 2 \mathrm{H}), 2.58-2.62(\mathrm{~m}, 6 \mathrm{H}), 3.48-3.52(\mathrm{~m}, 4 \mathrm{H}), 5.05-5.11$ $(\mathrm{t}, 1 \mathrm{H}, J=5.6 \mathrm{~Hz}), 6.63-6.75(\mathrm{~m}, 3 \mathrm{H}), 7.08(\mathrm{~d}, 2 \mathrm{H}, J=7.6 \mathrm{~Hz})$, 7.18-7.31 (m, 5H). ESIMS (M+H) ${ }^{+} m / z: 297$. 
3-(4-Benzylpiperazin-1-yl)-1-phenylpropan-1-ol (AM5a)

Yield: 90\%; IR (KBr) $v_{\max } \mathrm{cm}^{-1}: 3364,3226,3072$, 2928, 2812, 1611, 1516, 1446, 1244. ${ }^{1} \mathrm{H}$ NMR $(400 \mathrm{MHz}$, $\left.\mathrm{CDCl}_{3}\right)$ : 1.91-1.96 (m, 2H), $2.47(\mathrm{~m}, 4 \mathrm{H}), 2.53-2.56(\mathrm{~m}, 6 \mathrm{H})$, $3.59(\mathrm{~s}, 2 \mathrm{H}), 4.85(\mathrm{t}, 1 \mathrm{H}, J=5.8 \mathrm{~Hz}), 7.21-7.35(\mathrm{~m}, 10 \mathrm{H})$. ESIMS $(\mathrm{M}+\mathrm{H})^{+} m / z: 311$.

\section{3-(4-Benzylpiperidin-1-yl)-1-phenylpropan-1-ol (AM6a)}

Yield: 90\%; IR (KBr) $v_{\max } \mathrm{cm}^{-1}: 3223,3082,2921,2877$, 2824, 2364, 1611, 1498, 1450, 1361, 1311, 1250, 1163, 1105. ${ }^{1} \mathrm{H}$ NMR (400 MHz, $\left.\mathrm{CDCl}_{3}\right)$ : 1.29-1.45 (m, 4H), 1.62-1.91 (m, 3H), 2.27-2.31 (m, 4H), $2.55(\mathrm{brd}, 2 \mathrm{H}), 2.72(\mathrm{t}, 2 \mathrm{H}, J=5 \mathrm{~Hz}), 5.12(\mathrm{~m}$, $1 \mathrm{H}), 7.14-7.27(\mathrm{~m}, 10 \mathrm{H})$. ESIMS $(\mathrm{M}+\mathrm{H})^{+} \mathrm{m} / z: 310$.

Synthesis of compounds AM1b-6g: The target compounds were obtained by Mitsunobu reaction between the secondary alcohol and substituted phenol. A solution of diethyl azo di carboxylate (DEAD) $(55 \mathrm{mmol})$ in $25 \mathrm{~mL}$ of THF was added dropwise to a stirred solution of the alcohol (1a-6a, $50 \mathrm{mmol})$, phenol/substituted phenol (55 $\mathrm{mmol})$ and triphenylphosphine $(55 \mathrm{mmol})$ in $50 \mathrm{~mL}$ of THF. Stirring was continued at room temperature until thin layer chromatography indicated the absence of alcohol (12-18 hours). The mixture was then concentrated under reduced pressure. The crude mixture was subjected to flash chromatography to obtain the pure product as viscous, colorless to brown colored oil with an overall yield of $65-88 \%$.

\section{N,N-Diethyl-3-phenoxy-3-phenylpropan-1-amine (AM1b)}

Yield: 83\%; IR (KBr) $v_{\max } \mathrm{cm}^{-1}: 3259,3081,2924,2827$, $2788,1605,1466,1382,1259,1042 .{ }^{1} \mathrm{H} \mathrm{NMR}\left(400 \mathrm{MHz}, \mathrm{CDCl}_{3}\right)$ : $1.06(\mathrm{t}, 6 \mathrm{H}, J=7.2 \mathrm{~Hz}), 2.22-2.28(\mathrm{~m}, 2 \mathrm{H}), 2.48-2.61(\mathrm{~m}, 6 \mathrm{H})$, 5.29-5.38 (m, 1H), $6.88(\mathrm{~d}, 2 \mathrm{H}, J=8 \mathrm{~Hz}), 7.25-7.52(\mathrm{~m}, 8 \mathrm{H})$. ESIMS (M+H) $m / z: 284$.

\section{N,N-Diethyl-3-phenyl-3-(p-tolyloxy)propan-1-amine(AM1c)}

Yield: 70\%; IR (KBr) $v_{\max } \mathrm{cm}^{-1}: 3075,2889,1601,1466$, 1265, 1065. ${ }^{1} \mathrm{H}$ NMR (400 MHz, $\left.\mathrm{CDCl}_{3}\right): 1.08(\mathrm{t}, 6 \mathrm{H}, J=7.2 \mathrm{~Hz})$, $2.18-2.26(\mathrm{~m}, 2 \mathrm{H}), 2.42-2.55(\mathrm{~m}, 6 \mathrm{H}), 5.09-5.21(\mathrm{~m}, 1 \mathrm{H}), 6.78(\mathrm{~d}$, $2 \mathrm{H}, J=8 \mathrm{~Hz}), 7.11(\mathrm{~d}, 2 \mathrm{H}, J=8.2 \mathrm{~Hz}), 7.22-7.30(\mathrm{~m}, 5 \mathrm{H})$. ESIMS $(\mathrm{M}+\mathrm{H})^{+} m / z: 298$.

\section{3-(4-Bromophenoxy)- $N, N$-diethyl-3-phenylpropan-1-amine (AM1d)}

Yield:72\%; IR (KBr) $v_{\max } \mathrm{cm}^{-1}: 3085,2911,2872,1596$, $1461,1385,1245,1070 .{ }^{1} \mathrm{H}$ NMR $\left(400 \mathrm{MHz}, \mathrm{CDCl}_{3}\right): 1.08$ (t, 6H, $J=7.2 \mathrm{~Hz}), 2.24-2.36(\mathrm{~m}, 2 \mathrm{H}), 2.48-2.62(\mathrm{~m}, 6 \mathrm{H}), 5.22-5.35(\mathrm{~m}$, $1 \mathrm{H}), 6.81(\mathrm{~d}, 2 \mathrm{H}, J=7.6 \mathrm{~Hz}), 7.19-7.31(\mathrm{~m}, 5 \mathrm{H}), 7.33(\mathrm{~d}, 2 \mathrm{H}, J=$ 7.6Hz). ESIMS $(\mathrm{M}+\mathrm{H})^{+} m / z: 362$.

\section{$N, N$-Diethyl-3-(4-fluorophenoxy)-3-phenylpropan-1-amine (AM1e)}

Yield: 82\%; IR (KBr) $v_{\max } \mathrm{cm}^{-1}: 3068,2941,2850,2745$, $1608,1391,1268,1065 .{ }^{1} \mathrm{H}$ NMR $\left(400 \mathrm{MHz}, \mathrm{CDCl}_{3}\right): 1.06(\mathrm{t}, 6 \mathrm{H}$, $J=7.2 \mathrm{~Hz}), 2.28-2.35(\mathrm{~m}, 2 \mathrm{H}), 2.42-2.51(\mathrm{~m}, 6 \mathrm{H}), 5.30-5.44(\mathrm{~m}$, $1 \mathrm{H}), 6.88(\mathrm{~d}, 2 \mathrm{H}, J=8.2 \mathrm{~Hz}), 6.92(\mathrm{~d}, 2 \mathrm{H}, J=8.4 \mathrm{~Hz}), 7.21-7.38$ $(\mathrm{m}, 5 \mathrm{H})$. ESIMS $(\mathrm{M}+\mathrm{H})^{+} \mathrm{m} / z: 302$.
3-(4-Chlorophenoxy)-N,N-diethyl-3-phenylpropan-1-amine (AM1f)

Yield: 85\%; IR (KBr) $v_{\max } \mathrm{cm}^{-1}: 3105,3082,2908,2857$, $1608,1461,1373,1275,1068 .{ }^{1} \mathrm{H}$ NMR $\left(400 \mathrm{MHz}, \mathrm{CDCl}_{3}\right): 1.08$ $(\mathrm{t}, 6 \mathrm{H}, J=7.2 \mathrm{~Hz}), 2.24-2.36(\mathrm{~m}, 2 \mathrm{H}), 2.44-2.56(\mathrm{~m}, 6 \mathrm{H}), 5.25-$ $5.39(\mathrm{~m}, 1 \mathrm{H}), 6.80(\mathrm{~d}, 2 \mathrm{H}, J=7.8 \mathrm{~Hz}), 7.19-7.38(\mathrm{~m}, 7 \mathrm{H})$. ESIMS $(\mathrm{M}+\mathrm{H})^{+} m / z: 318$.

\section{N,N-Diethyl-3-phenyl-3-(4-(trifluoromethyl)phenoxy)propan-1-} amine (AM1g)

Yield: $85 \%$; IR (KBr) $v_{\max } \mathrm{cm}^{-1}: 3101,3085,2911,2870$, $1605,1599,1380,169,1073 .{ }^{1} \mathrm{H}$ NMR $\left(400 \mathrm{MHz}, \mathrm{CDCl}_{3}\right): 1.08$ (t, $6 \mathrm{H}, J=7.2 \mathrm{~Hz}), 2.32-2.36(\mathrm{~m}, 2 \mathrm{H}), 2.48-2.55(\mathrm{~m}, 6 \mathrm{H}), 5.28-5.42$ $(\mathrm{m}, 1 \mathrm{H}), 6.82(\mathrm{~d}, 2 \mathrm{H}, J=8 \mathrm{~Hz}), 7.25-7.42(\mathrm{~m}, 5 \mathrm{H}), 7.43-7.55(\mathrm{~d}$, $2 \mathrm{H}, J=7.9 \mathrm{~Hz})$. ESIMS $(\mathrm{M}+\mathrm{H})^{+} m / z: 352$.

\section{4-(3-Phenoxy-3-phenylpropyl)morpholine (AM2b)}

Yield: 80\%; IR (KBr) $v_{\max } \mathrm{cm}^{-1}: 3108,2912,1612,1459$, 1385, 1252, 1071. ${ }^{1} \mathrm{H}$ NMR (400 MHz, $\left.\mathrm{CDCl}_{3}\right): 1.93$ (m, 1H), 2.14 $(\mathrm{m}, 1 \mathrm{H}), 2.35-2.69(\mathrm{~m}, 6 \mathrm{H}), 3.56(\mathrm{t}, 4 \mathrm{H}, J=6.2 \mathrm{~Hz}), 5.11(\mathrm{~m}, 1 \mathrm{H})$, $6.82(\mathrm{dd}, 2 \mathrm{H}, J=8.2 \mathrm{~Hz}), 7.12-7.35(\mathrm{~m}, 7 \mathrm{H}) . \operatorname{ESIMS}(\mathrm{M}+\mathrm{H})^{+}$ $m / z: 298$.

\section{4-(3-Phenyl-3-(p-tolyloxy)propyl)morpholine (AM2c)}

Yield: 72\%; IR (KBr) $v_{\max } \mathrm{cm}^{-1}: 3081,2095,1608,1462$, 1261, $1068 .{ }^{1} \mathrm{H}$ NMR (400 MHz, $\left.\mathrm{CDCl}_{3}\right): 1.90(\mathrm{t}, 2 \mathrm{H}, J=5.2 \mathrm{~Hz})$, $2.11(\mathrm{~m}, 4 \mathrm{H}), 2.30(\mathrm{~s}, 3 \mathrm{H}), 2.34-2.70(\mathrm{~m}, 4 \mathrm{H}), 3.52(\mathrm{t}, 2 \mathrm{H}, J=$ $5.6 \mathrm{~Hz}), 5.19(\mathrm{~m}, 1 \mathrm{H}), 6.78(\mathrm{~d}, 2 \mathrm{H}, J=8 \mathrm{~Hz}), 7.08(\mathrm{~d}, 2 \mathrm{H} J=$ 7.2Hz), 7.21-7.32 (m, 5H). ESIMS (M+H) ${ }^{+} m / z: 312$.

\section{4-(3-(4-Bromophenoxy)-3-phenylpropyl)morpholine (AM2d)}

Yield: 65\%; IR (KBr) $v_{\max } \mathrm{cm}^{-1}: 3088,2915,2872,1611$, 1465, 1385, 1242, 1068. ${ }^{1} \mathrm{H}$ NMR (400 MHz, $\left.\mathrm{CDCl}_{3}\right): 1.92(\mathrm{t}, 2 \mathrm{H}$, $J=5.2 \mathrm{~Hz}), 2.12(\mathrm{~m}, 4 \mathrm{H}), 2.35(\mathrm{~s}, 3 \mathrm{H}), 3.55(\mathrm{t}, 2 \mathrm{H}, J=5.2 \mathrm{~Hz})$, $5.08-5.15(\mathrm{~m}, 1 \mathrm{H}), 6.86(\mathrm{~d}, 2 \mathrm{H}, J=7.8 \mathrm{~Hz}), 7.18(\mathrm{~d}, 2 \mathrm{H} J=$ 7.9Hz), 7.20-7.32 (m, 5H). ESIMS (M+H) ${ }^{+} m / z: 376$.

\section{4-(3-(4-Fluorophenoxy)-3-phenylpropyl)morpholine (AM2e)}

Yield: 70\%; IR (KBr) $v_{\max } \mathrm{cm}^{-1}: 3069,2948,2865,1605$, 1390, 1262, 1065. ${ }^{1} \mathrm{H}$ NMR (400 MHz, $\left.\mathrm{CDCl}_{3}\right): 1.90$ (t, 2H, $J=$ $5.2 \mathrm{~Hz}), 2.14(\mathrm{~m}, 4 \mathrm{H}), 2.34(\mathrm{~s}, 3 \mathrm{H}), 3.56(\mathrm{t}, 2 \mathrm{H}, J=5.6 \mathrm{~Hz}), 5.21-$ $5.28(\mathrm{~m}, 1 \mathrm{H}), 6.81(\mathrm{~d}, 2 \mathrm{H}, J=8 \mathrm{~Hz}), 7.16(\mathrm{~d}, 2 \mathrm{H} J=7.2 \mathrm{~Hz})$, 7.19-7.32 (m, 5H). ESIMS (M+H) $)^{+} m / z: 316$.

\section{4-(3-(4-Chlorophenoxy)-3-phenylpropyl)morpholine (AM2f)}

Yield: 70\%; IR (KBr) $v_{\text {max }} \mathrm{cm}^{-1}: 3101,3088,2911,2852$, 1608, 1463, 1373, 1265, 1069. ${ }^{1} \mathrm{H}$ NMR (400 MHz, $\left.\mathrm{CDCl}_{3}\right): 1.92$ $(\mathrm{t}, 2 \mathrm{H}, J=5.2 \mathrm{~Hz}), 2.12(\mathrm{~m}, 4 \mathrm{H}), 2.31(\mathrm{~s}, 3 \mathrm{H}), 3.54(\mathrm{t}, 2 \mathrm{H}, J=$ $5.6 \mathrm{~Hz}), 5.14(\mathrm{~m}, 1 \mathrm{H}), 6.79(\mathrm{~d}, 2 \mathrm{H}, J=7.6 \mathrm{~Hz}), 7.20(\mathrm{~d}, 2 \mathrm{H} J=$ $7.2 \mathrm{~Hz}), 721-7.35$ (m, 5H). ESIMS (M+H) ${ }^{+} m / z: 332$.

4-(3-Phenyl-3-(4-(trifluoromethyl) phenoxy)propyl)morpholine (AM2g)

Yield: 72\%; IR (KBr) $v_{\max } \mathrm{cm}^{-1}: 3095,3069,2908,2811$, 1605, 1609, 1385, 1262, 1085. ${ }^{1} \mathrm{H}$ NMR (400 MHz, $\left.\mathrm{CDCl}_{3}\right): 1.91$ $(\mathrm{t}, 2 \mathrm{H}, J=5.2 \mathrm{~Hz}), 2.13(\mathrm{~m}, 4 \mathrm{H}), 2.36-2.68(\mathrm{~m}, 4 \mathrm{H}), 3.59(\mathrm{t}, 2 \mathrm{H}$, $J=5.2 \mathrm{~Hz}), 5.26(\mathrm{~m}, 1 \mathrm{H}), 6.78(\mathrm{~d}, 2 \mathrm{H}, J=7.2 \mathrm{~Hz}), 7.31-7.49(\mathrm{~m}$, 
$5 \mathrm{H}), 7.61(\mathrm{~d}, 2 \mathrm{H} J=7.2 \mathrm{~Hz})$. ESIMS $(\mathrm{M}+\mathrm{H})^{+} m / z: 366$.

\section{1-(3-Phenoxy-3-phenylpropyl)piperidine (AM3b)}

Yield: $85 \%$; IR (KBr) $v_{\max } \mathrm{cm}^{-1}: 3115,2928,2854,1568$, 1357, 1249, 1069. ${ }^{1} \mathrm{H}$ NMR (400 $\left.\mathrm{MHz}^{\operatorname{mad}} \mathrm{CDCl}_{3}\right): 1.22-1.40(\mathrm{~m}$, $6 \mathrm{H}), 1.85(\mathrm{~m}, 1 \mathrm{H}), 2.09(\mathrm{~m}, 1 \mathrm{H}), 2.21(\mathrm{~m}, 4 \mathrm{H}), 2.28(\mathrm{~m}, 2 \mathrm{H})$, $4.98(\mathrm{~m}, 1 \mathrm{H}), 6.74(\mathrm{~d}, 2 \mathrm{H}, J=8 \mathrm{~Hz}), 7.11-7.26(\mathrm{~m}, 8 \mathrm{H})$. ESIMS $(\mathrm{M}+\mathrm{H})^{+} m / z: 296$.

\section{1-(3-Phenyl-3-(p-tolyloxy)propyl)piperidine (AM3c)}

Yield: 75\%; IR (KBr) $v_{\text {max }} \mathrm{cm}^{-1}: 3098,2892,1608,1456$, 1261, 1071. ${ }^{1} \mathrm{H}$ NMR $\left(400 \mathrm{MHz}, \mathrm{CDCl}_{3}\right): 1.20-1.35$ (m, 6H), 1.83 (m, 1H), $2.10(\mathrm{~m}, 1 \mathrm{H}), 2.19-2.23(\mathrm{~m}, 4 \mathrm{H}), 2.25(\mathrm{~m}, 2 \mathrm{H}), 2.32(\mathrm{~s}$, $3 \mathrm{H}), 5.02(\mathrm{~m}, 1 \mathrm{H}), 6.76(\mathrm{~d}, 2 \mathrm{H}, J=7.6 \mathrm{~Hz}), 7.06(\mathrm{~d}, 2 \mathrm{H}, J=$ 7.6Hz), 7.19-7.30 (m, 5H). ESIMS (M+H) $m / z: 310$.

\section{1-(3-(4-Bromophenoxy)-3-phenylpropyl)piperidine (AM3d)}

Yield: 68\%; IR (KBr) $v_{\text {max }} \mathrm{cm}^{-1}: 3085,2908,2875,1606$, 1460, 1391, 1253, 1074. ${ }^{1} \mathrm{H}$ NMR (400 $\left.\mathrm{MHz}, \mathrm{CDCl}_{3}\right)$ : 1.18-1.36 $(\mathrm{m}, 6 \mathrm{H}), 1.85(\mathrm{~m}, 1 \mathrm{H}), 2.12(\mathrm{~m}, 1 \mathrm{H}), 2.19-2.24(\mathrm{~m}, 4 \mathrm{H}), 2.28(\mathrm{~m}$, $2 \mathrm{H}), 5.11(\mathrm{~m}, 1 \mathrm{H}), 6.81(\mathrm{~d}, 2 \mathrm{H}, J=8.6 \mathrm{~Hz}), 7.16(\mathrm{~d}, 2 \mathrm{H}, J=$ 8.2Hz), 7.21-7.33 (m, 5H). ESIMS (M+H) ${ }^{+} \mathrm{m} / z: 374$.

\section{1-(3-(4-Fluorophenoxy)-3-phenylpropyl)piperidine (AM3e)}

Yield: 70\%; IR (KBr) $v_{\max } \mathrm{cm}^{-1}: 3072,2909,2862,1608$, 1408, 1272, 1085. ${ }^{1} \mathrm{H}$ NMR (400 $\left.\mathrm{MHz}_{2} \mathrm{CDCl}_{3}\right): 1.22-1.39(\mathrm{~m}$, $6 \mathrm{H}), 1.81(\mathrm{~m}, 1 \mathrm{H}), 2.09(\mathrm{~m}, 1 \mathrm{H}), 2.20-2.24(\mathrm{~m}, 4 \mathrm{H}), 2.29(\mathrm{~m}, 2 \mathrm{H})$, $5.14(\mathrm{~m}, 1 \mathrm{H}), 6.75(\mathrm{~d}, 2 \mathrm{H}, J=6.8 \mathrm{~Hz}), 7.13(\mathrm{~d}, 2 \mathrm{H}, J=6.6 \mathrm{~Hz})$, 7.21-7.33 (m, 5H). ESIMS $(\mathrm{M}+\mathrm{H})^{+} m / z: 314$.

\section{1-(3-(4-Chlorophenoxy)-3-phenylpropyl)piperidine (AM3f)}

Yield: 65\%; IR (KBr) $v_{\max } \mathrm{cm}^{-1}: 3112,3088,2915,2806$, $1611,1455,1369,1271,1058 .{ }^{1} \mathrm{H}$ NMR $\left(400 \mathrm{MHz}, \mathrm{CDCl}_{3}\right): 1.18$ $1.36(\mathrm{~m}, 6 \mathrm{H}), 1.85(\mathrm{~m}, 1 \mathrm{H}), 2.12(\mathrm{~m}, 1 \mathrm{H}), 2.19-2.24(\mathrm{~m}, 4 \mathrm{H}), 2.28$ $(\mathrm{m}, 2 \mathrm{H}), 5.11(\mathrm{~m}, 1 \mathrm{H}), 6.81(\mathrm{~d}, 2 \mathrm{H}, J=7.6 \mathrm{~Hz}), 7.16(\mathrm{~d}, 2 \mathrm{H}, J=$ $7.56 \mathrm{~Hz}), 7.21-7.33(\mathrm{~m}, 5 \mathrm{H})$. ESIMS $(\mathrm{M}+\mathrm{H})^{+} \mathrm{m} / z: 330$.

\section{1-(3-Phenyl-3-(4-(trifluoromethyl)-phenoxy)propyl)piperidine (AM3g)}

Yield: 75\%; IR (KBr) $v_{\max } \mathrm{cm}^{-1}: 3109,3065,2962,2829$, 1601, 1429, 1378, 1268, 1071. ${ }^{1} \mathrm{H}$ NMR (400 MHz, $\left.\mathrm{CDCl}_{3}\right): 1.24$ $(\mathrm{m}, 2 \mathrm{H}), 1.41(\mathrm{~m}, 4 \mathrm{H}), 1.85(\mathrm{~m}, 1 \mathrm{H}), 2.07(\mathrm{~m}, 1 \mathrm{H}), 2.20-2.28$ $(\mathrm{m}, 6 \mathrm{H}), 5.23(\mathrm{~m}, 1 \mathrm{H}), 6.74(\mathrm{~d}, 2 \mathrm{H}, J=8 \mathrm{~Hz}), 7.11(\mathrm{~d}, 2 \mathrm{H}, J=$ $7.92 \mathrm{~Hz}), 7.20(\mathrm{~m}, 5 \mathrm{H})$. ESIMS $(\mathrm{M}+\mathrm{H})^{+} m / z: 364$.

\section{1-(3-Phenoxy-3-phenylpropyl)-4-phenylpiperazine (AM4b)}

Yield: 67\%; IR (KBr) $v_{\max } \mathrm{cm}^{-1}: 3109,3082,2961,2837$, $1611,1445,1384,1271,1068 .{ }^{1} \mathrm{H}$ NMR $\left(400 \mathrm{MHz}, \mathrm{CDCl}_{3}\right)$ : $1.97-$ $2.05(\mathrm{~m}, 2 \mathrm{H}), 2.56-2.63(\mathrm{~m}, 6 \mathrm{H}), 3.45-3.52(\mathrm{~m}, 4 \mathrm{H}), 5.11-5.14(\mathrm{~m}$, $1 \mathrm{H}), 6.68(\mathrm{~d}, 2 \mathrm{H}, J=8 \mathrm{~Hz}), 6.81(\mathrm{~d}, 2 \mathrm{H}, J=7.6 \mathrm{~Hz}), 7.08-7.31$ $(\mathrm{m}, 11 \mathrm{H})$. ESIMS $(\mathrm{M}+\mathrm{H})^{+} \mathrm{m} / z: 373$.

\section{1-Phenyl-4-(3-phenyl-3-(p-tolyloxy)propyl)piperazine (AM4c)}

Yield: $80 \%$; IR (KBr) $v_{\max } \mathrm{cm}^{-1}: 3115,3075,2889,1601$, 1465, 1265, 1068. ${ }^{1} \mathrm{H}$ NMR (400 MHz, $\left.\mathrm{CDCl}_{3}\right): 1.92-2.01(\mathrm{~m}$, $2 \mathrm{H}), 2.35(\mathrm{~s}, 3 \mathrm{H}), 2.54-2.62(\mathrm{~m}, 6 \mathrm{H}), 3.46-3.55(\mathrm{~m}, 4 \mathrm{H}), 5.04-5.10$ $(\mathrm{m}, 1 \mathrm{H}), 6.65(\mathrm{~d}, 2 \mathrm{H}, J=7.8 \mathrm{~Hz}), 6.82(\mathrm{~d}, 2 \mathrm{H}, J=8 \mathrm{~Hz}), 7.08(\mathrm{~d}$, $2 \mathrm{H}, J=8 \mathrm{~Hz}), 7.10-7.30(\mathrm{~m}, 8 \mathrm{H})$. ESIMS (M+H) ${ }^{+} \mathrm{m} / z: 387$.
1-(3-(4-Bromophenoxy)-3-phenylpropyl)-4-phenylpiperazine (AM4d)

Yield: $82 \%$; IR (KBr) $v_{\text {max }} \mathrm{cm}^{-1}: 3105,3046,2925,2883$, $1598,1461,1388,1252,1074 .{ }^{1} \mathrm{H}^{\max } \mathrm{NMR}\left(400 \mathrm{MHz} \mathrm{CDCl}_{3}\right): 1.94-$ $2.05(\mathrm{~m}, 2 \mathrm{H}), 2.55-2.62(\mathrm{~m}, 6 \mathrm{H}), 3.48-3.52(\mathrm{~m}, 4 \mathrm{H}), 5.09-5.13(\mathrm{~m}$, $1 \mathrm{H}), 6.72(\mathrm{~d}, 2 \mathrm{H}, J=8 \mathrm{~Hz}), 6.81(\mathrm{~d}, 2 \mathrm{H}, J=8.6 \mathrm{~Hz}), 7.08(\mathrm{~m}$, $1 \mathrm{H}), 7.16(\mathrm{~d}, 2 \mathrm{H}, J=8.4 \mathrm{~Hz}), 7.21-7.34(\mathrm{~m}, 7 \mathrm{H})$. ESIMS $(\mathrm{M}+\mathrm{H})^{+}$ $m / z: 451$.

\section{1-(3-(4-Fluorophenoxy)-3-phenylpropyl)-4-phenylpiperazine (AM4e)}

Yield: 85\%; IR (KBr) $v_{\max } \mathrm{cm}^{-1}: 3115,3068,2950$, 2842, 2721, 1601, 1390, 1275, 1068. ${ }^{1} \mathrm{H}$ NMR $(400 \mathrm{MHz}$, $\left.\mathrm{CDCl}_{3}\right): 1.89-2.01(\mathrm{~m}, 2 \mathrm{H}), 2.55-2.63(\mathrm{~m}, 6 \mathrm{H}), 3.46-3.58(\mathrm{~m}$, $4 \mathrm{H}), 5.21-5.28(\mathrm{~m}, 1 \mathrm{H}), 6.75(\mathrm{~d}, 2 \mathrm{H}, J=7.54 \mathrm{~Hz}), 6.79(\mathrm{~d}, 2 \mathrm{H}$, $J=7.6 \mathrm{~Hz}), 7.13(\mathrm{~m}, 3 \mathrm{H}), 7.23-7.42(\mathrm{~m}, 7 \mathrm{H})$. ESIMS $(\mathrm{M}+\mathrm{H})^{+}$ $\mathrm{m} / \mathrm{z}: 391$.

1-(3-(4-Chlorophenoxy)-3-phenylpropyl)-4-phenylpiperazine (AM4f)

Yield: $80 \%$; IR (KBr) $v_{\text {max }} \mathrm{cm}^{-1}: 3105,3085,2918,2855$, $1611,1465,1372,1276,1074 .{ }^{1} \mathrm{H}$ NMR $\left(400 \mathrm{MHz}^{\mathrm{max}} \mathrm{CDCl}_{3}\right)$ : $1.92-$ $2.05(\mathrm{~m}, 2 \mathrm{H}), 2.55-2.62(\mathrm{~m}, 6 \mathrm{H}), 3.48-3.52(\mathrm{~m}, 4 \mathrm{H}), 5.09-5.13(\mathrm{~m}$, $1 \mathrm{H}), 6.74(\mathrm{~d}, 2 \mathrm{H}, J=8.2 \mathrm{~Hz}), 6.81(\mathrm{~d}, 2 \mathrm{H}, J=8 \mathrm{~Hz}), 7.07(\mathrm{~m}$, $1 \mathrm{H}), 7.18(\mathrm{~d}, 2 \mathrm{H}, J=8.6 \mathrm{~Hz}), 7.21-7.33(\mathrm{~m}, 7 \mathrm{H})$. ESIMS $(\mathrm{M}+\mathrm{H})^{+}$ $m / z: 407$.

\section{1-Phenyl-4-(3-phenyl-3-(4-(trifluoromethyl)phenoxy)propyl) piperazine (AM4g)}

Yield: $85 \%$; IR (KBr) $v_{\text {max }} \mathrm{cm}^{-1}: 3101,3082,2911,2870$, $1605,1605,1380,1265,1071 .{ }^{1} \mathrm{H}$ NMR $\left(400 \mathrm{MHz}, \mathrm{CDCl}_{3}\right): 1.93-$ $2.01(\mathrm{~m}, 2 \mathrm{H}), 2.55-2.62(\mathrm{~m}, 6 \mathrm{H}), 3.46-3.55(\mathrm{~m}, 4 \mathrm{H}), 5.17-5.21(\mathrm{~m}$, $1 \mathrm{H}), 6.74(\mathrm{~d}, 2 \mathrm{H}, J=7.2 \mathrm{~Hz}), 6.81(\mathrm{~d}, 2 \mathrm{H}, J=7.6 \mathrm{~Hz}), 7.03-7.09$ $(\mathrm{m}, 2 \mathrm{H}), 7.20-7.31(\mathrm{~m}, 7 \mathrm{H})$. ESIMS $(\mathrm{M}+\mathrm{H})^{+} \mathrm{m} / z: 441$.

\section{1-Benzyl-4-(3-phenoxy-3-phenylpropyl)piperazine (AM5b)}

Yield: 70\%; IR (KBr) $v_{\max } \mathrm{cm}^{-1}: 3128,3081,2924,2827$, $2795,1612,1382,1255,1069 .{ }^{1} \mathrm{H}$ NMR $\left(400 \mathrm{MHz}, \mathrm{CDCl}_{3}\right)$ : $1.94-$ $2.05(\mathrm{~m}, 2 \mathrm{H}), 2.47(\mathrm{~m}, 4 \mathrm{H}), 2.53-2.56(\mathrm{~m}, 6 \mathrm{H}), 3.59(\mathrm{~s}, 2 \mathrm{H})$, $5.12-5.25(\mathrm{~m}, 1 \mathrm{H}), 6.82(\mathrm{~d}, 2 \mathrm{H}, J=8.2 \mathrm{~Hz}), 7.16-7.35(\mathrm{~m}, 13 \mathrm{H})$. ESIMS $(\mathrm{M}+\mathrm{H})^{+} m / z: 387$.

\section{1-Benzyl-4-(3-phenyl-3-(p-tolyloxy)propyl)piperazine (AM5c)}

Yield: 70\%; IR (KBr) $v_{\max } \mathrm{cm}^{-1}: 3095,3012,2924,2805$, 1615, 1422, 1275, 1076. ${ }^{1} \mathrm{H}$ NMR (400 MHz, $\left.\mathrm{CDCl}_{3}\right): 1.93-2.01$ $(\mathrm{m}, 2 \mathrm{H}), 2.31(\mathrm{~s}, 3 \mathrm{H}), 2.44(\mathrm{~m}, 4 \mathrm{H}), 2.52-2.56(\mathrm{~m}, 4 \mathrm{H}), 3.59(\mathrm{~s}$, $2 \mathrm{H}), 4.85-4.91(\mathrm{~m}, 1 \mathrm{H}), 6.68(\mathrm{~d}, 2 \mathrm{H}, J=7.8 \mathrm{~Hz}), 6.81(\mathrm{~d}, 2 \mathrm{H}, J=$ $7.2 \mathrm{~Hz}), 7.10(\mathrm{~d}, 2 \mathrm{H}, J=8 \mathrm{~Hz}), 7.13-7.30(\mathrm{~m}, 8 \mathrm{H})$. ESIMS $(\mathrm{M}+\mathrm{H})^{+}$ $\mathrm{m} / \mathrm{z}: 401$.

\section{1-Benzyl-4-(3-(4-bromophenoxy)-3-phenylpropyl)piperazine (AM5d)}

Yield: 75\%; IR (KBr) $v_{\max } \mathrm{cm}^{-1}: 3085,2911,2872,1614$, 1437, 1365, 1258, 1075. ${ }^{1} \mathrm{H}$ NMR (400 $\left.\mathrm{MHz}, \mathrm{CDCl}_{3}\right): 1.91-2.02$ $(\mathrm{m}, 2 \mathrm{H}), 2.41(\mathrm{~m}, 4 \mathrm{H}), 2.49-2.55(\mathrm{~m}, 4 \mathrm{H}), 3.55(\mathrm{~s}, 2 \mathrm{H}), 5.02-5.16$ $(\mathrm{m}, 1 \mathrm{H}), 6.81(\mathrm{~d}, 2 \mathrm{H}, J=8.4 \mathrm{~Hz}), 7.16(\mathrm{~d}, 2 \mathrm{H}, J=7.6 \mathrm{~Hz}), 7.21-$ $7.34(\mathrm{~m}, 10 \mathrm{H})$. ESIMS $(\mathrm{M}+\mathrm{H})^{+} m / z: 465$. 
1-Benzyl-4-(3-(4-fluorophenoxy)-3-phenylpropyl)piperazine (AM5e)

Yield: 75\%; IR (KBr) $v_{\text {max }} \mathrm{cm}^{-1}: 3068,2941,2850,2745$, 1608, 1391, 1268, 1065. ${ }^{1} \mathrm{H}$ NMR (400 MHz, $\left.\mathrm{CDCl}_{3}\right): 1.89-2.01$ $(\mathrm{m}, 2 \mathrm{H}), 2.52-2.63(\mathrm{~m}, 6 \mathrm{H}), 3.46-3.53(\mathrm{~m}, 4 \mathrm{H}), 3.56(\mathrm{~s}, 2 \mathrm{H}), 5.15-$ $5.19(\mathrm{~m}, 1 \mathrm{H}), 6.78(\mathrm{~d}, 2 \mathrm{H}, J=8 \mathrm{~Hz}), 6.95(\mathrm{~d}, 2 \mathrm{H}, J=7.5 \mathrm{~Hz})$, 7.19-7.33 (m, 10H). ESIMS $(\mathrm{M}+\mathrm{H})^{+} m / z: 405$.

\section{1-Benzyl-4-(3-(4-chlorophenoxy)-3-phenylpropyl)piperazine (AM5f)}

Yield: 72\%; IR (KBr) $v_{\max } \mathrm{cm}^{-1}: 3115,3083,2905,2863$, $1605,1452,1373,1278,1075 .{ }^{1} \mathrm{H}$ NMR $\left(400 \mathrm{MHz} \mathrm{CDCl}_{3}\right): 1.92-$ $2.05(\mathrm{~m}, 2 \mathrm{H}), 2.55-2.62(\mathrm{~m}, 6 \mathrm{H}), 3.48-3.52(\mathrm{~m}, 4 \mathrm{H}), 5.09-5.13(\mathrm{~m}$, $1 \mathrm{H}), 6.83(\mathrm{~d}, 2 \mathrm{H}, J=8 \mathrm{~Hz}), 7.16(\mathrm{~d}, 2 \mathrm{H}, J=8.2 \mathrm{~Hz}), 7.21-7.33$ $(\mathrm{m}, 10 \mathrm{H})$; ESIMS $(\mathrm{M}+\mathrm{H})^{+} m / z: 421$.

\section{1-Benzyl-4-(3-phenyl-3-(4-(trifluoromethyl)phenoxy)propyl) piperazine (AM5g)}

Yield: $80 \%$; IR (KBr) $v_{\max } \mathrm{cm}^{-1}: 3101,3085,2911$, 2870, 1605, 1599, 1380, 1269, 1073. ${ }^{1} \mathrm{H}$ NMR (400 MHz, $\left.\mathrm{CDCl}_{3}\right): 1.85-2.04(\mathrm{~m}, 2 \mathrm{H}), 2.34(\mathrm{~m}, 4 \mathrm{H}), 2.51-2.60(\mathrm{~m}, 6 \mathrm{H})$, $3.58(\mathrm{~s}, 2 \mathrm{H}), 5.14-5.19(1 \mathrm{H}, \mathrm{m}), 6.74(\mathrm{~d}, 2 \mathrm{H}, J=9.2 \mathrm{~Hz}), 6.81$ $(\mathrm{d}, 2 \mathrm{H}, J=8.6 \mathrm{~Hz}), 7.03-7.09(\mathrm{~m}, 2 \mathrm{H}), 7.20-7.31(\mathrm{~m}, 10 \mathrm{H})$; ESIMS $(\mathrm{M}+\mathrm{H})^{+} m / z: 455$.

\section{4-Benzyl-1-(3-phenoxy-3-phenylpropyl)piperidine (AM6b)}

Yield: 80\%; IR (KBr) $v_{\max } \mathrm{cm}^{-1}: 3119,3081,2924$, 2827, 2792, 1613, 1592, 1375, 1281, 1078; ${ }^{1} \mathrm{H}$ NMR $(400 \mathrm{MHz}$, $\left.\mathrm{CDCl}_{3}\right): 1.68-1.73(\mathrm{~m}, 5 \mathrm{H}), 1.84-1.91(\mathrm{~m}, 2 \mathrm{H}), 2.26-2.32(\mathrm{~m}$, $4 \mathrm{H}), 2.62(\mathrm{~d}, 2 \mathrm{H}, J=5.6 \mathrm{~Hz}), 2.65(\mathrm{~d}, 2 \mathrm{H}, J=4.8 \mathrm{~Hz}), 5.08$ $5.15(1 \mathrm{H}, \mathrm{m}), 6.85(\mathrm{~d}, 2 \mathrm{H}, J=7.6 \mathrm{~Hz}), 7.14-7.33(\mathrm{~m}, 13 \mathrm{H})$. ESIMS $(\mathrm{M}+\mathrm{H})^{+} m / z: 386$.

\section{4-Benzyl-1-(3-phenyl-3-(p-tolyloxy)propyl)piperidine (AM6c)}

Yield: $85 \%$; IR (KBr) $v_{\max } \mathrm{cm}^{-1}: 3086,2889,1611$, 1589, 1455, 1276, 1082, ${ }^{1} \mathrm{H}$ NMR (400 MHz, $\left.\mathrm{CDCl}_{3}\right): 1.61-1.72$ (m, 5H), 1.79-1.88 (m, 2H), 2.21-2.30 (m, 4H), 2.32 (s, 3H), 2.62 (brd, 2H), 2.67 (t, $2 \mathrm{H}, J=4.8 \mathrm{~Hz}), 5.03-5.15(1 \mathrm{H}, \mathrm{m}), 6.88(2 \mathrm{H}$, $J=8.2 \mathrm{~Hz}), 7.08(2 \mathrm{H}, J=7.8 \mathrm{~Hz}), 7.16-7.31(\mathrm{~m}, 10 \mathrm{H})$. ESIMS $(\mathrm{M}+\mathrm{H})^{+} \mathrm{m} / z: 400$.

\section{4-Benzyl-1-(3-(4-bromophenoxy)-3-phenylpropyl)piperidine (AM6d)}

Yield: 70\%; IR (KBr) $v_{\max } \mathrm{cm}^{-1}: 3115,3082,2905,2864$, $1609,1588,1461,1385,1262,1078 .{ }^{1} \mathrm{H} \mathrm{NMR}\left(400 \mathrm{MHz}, \mathrm{CDCl}_{3}\right)$ : $1.63-1.75(\mathrm{~m}, 5 \mathrm{H}), 1.80-1.87(\mathrm{~m}, 2 \mathrm{H}), 2.18-2.27(\mathrm{~m}, 4 \mathrm{H}), 2.66$ (brd, $2 \mathrm{H}), 2.65(\mathrm{t}, 2 \mathrm{H}, J=5.2 \mathrm{~Hz}), 5.12-5.19(1 \mathrm{H}, \mathrm{m}), 6.82(\mathrm{t}, 2 \mathrm{H}$, $J=6.8 \mathrm{~Hz}), 7.18(\mathrm{t}, 2 \mathrm{H}, J=7 \mathrm{~Hz}), 7.16-7.31(\mathrm{~m}, 10 \mathrm{H})$. ESIMS $(\mathrm{M}+\mathrm{H})^{+} m / z: 464$.

\section{4-Benzyl-1-(3-(4-fluorophenoxy)-3-phenylpropyl)piperidine (AM6e)}

Yield: 85\%; IR (KBr) $v_{\max } \mathrm{cm}^{-1}: 3068,2941,2850,2745$, 1608, 1391, 1268, 1065. ${ }^{1} \mathrm{H}$ NMR (400 MHz, $\left.\mathrm{CDCl}_{3}\right): 1.65-1.76$ (m, 5H), 1.80-1.87 (m, 2H), 2.18-2.37 (m, 4H), 2.64 (brd, 2H), 5.14-5.19 (1H, m), $6.79(\mathrm{t}, 2 \mathrm{H}, J=7.2 \mathrm{~Hz}), 7.01(\mathrm{t}, 2 \mathrm{H}, J=7 \mathrm{~Hz})$, 7.19-7.32 (m, 10H). ESIMS (M+H) ${ }^{+} m / z: 404$.
4-Benzyl-1-(3-(4-chlorophenoxy)-3-phenylpropyl)piperidine (AM6f)

Yield: 82\%; IR (KBr) $v_{\max } \mathrm{cm}^{-1}: 3105,3075,2918$, 2844, 1608, 1423, 1384, 1275, 1082. ${ }^{1} \mathrm{H}$ NMR $(400 \mathrm{MHz}$, $\left.\mathrm{CDCl}_{3}\right): 1.63-1.78(\mathrm{~m}, 5 \mathrm{H}), 1.80-1.85(\mathrm{~m}, 2 \mathrm{H}), 2.20-2.31(\mathrm{~m}$, $4 \mathrm{H}), 2.62$ (brd, 2H), $2.64(\mathrm{t}, 2 \mathrm{H}, J=5.2 \mathrm{~Hz}), 5.06-5.14(1 \mathrm{H}$, $\mathrm{m}), 6.84(\mathrm{~J}=7.4 \mathrm{~Hz}), 7.13(\mathrm{~J}=7.2 \mathrm{~Hz}), 7.16-7.29(\mathrm{~m}, 10 \mathrm{H})$; ESIMS $(\mathrm{M}+\mathrm{H})^{+} m / z: 420$.

\section{4-Benzyl-1-(3-phenyl-3-(4-(trifluoromethyl)phenoxy)propyl) piperidine (AM6g)}

Yield: 88\%; IR (KBr) $v_{\max } \mathrm{cm}^{-1}: 3105,3085,2911,2854$ $1609,1599,1380,1257,1078 .{ }^{1} \mathrm{H}$ NMR $\left(400 \mathrm{MHz} \mathrm{CDCl}_{3}\right): 1.61-$ $1.76(\mathrm{~m}, 5 \mathrm{H}), 1.83-185(\mathrm{~m}, 1 \mathrm{H}), 2.19-2.28(\mathrm{~m}, 4 \mathrm{H}), 2.60(\mathrm{~d}, 2 \mathrm{H}, J$ $=4.8 \mathrm{~Hz}), 2.65(\mathrm{t}, 2 \mathrm{H}, J=5.2 \mathrm{~Hz}), 5.11-5.15(\mathrm{~m}, 1 \mathrm{H}), 6.82(\mathrm{~d}, 2 \mathrm{H}$, $J=7.2 \mathrm{~Hz}), 7.18(\mathrm{~d}, 2 \mathrm{H}, J=7.4 \mathrm{~Hz}), 7.21-7.33$ (m, 10H). ESIMS $(\mathrm{M}+\mathrm{H})^{+} m / z: 454$.

\section{Bioactivity screening}

The synthesized compounds were tested for antimycobacterial activity against Mycobacterium tuberculosis H37Rv (ATCC 27294) by Microplate Alamar Blue Assay (MABA) method (Franzblau et al., 1998). To determine selective TB activity, they were also tested for antimicrobial activity. They were tested against Bacillus subtilis (ATCC 6633), Staphylococcus aureus (ATCC 25923), Pseudomonas aeruginosa (ATCC 27853) Escherichia coli (ATCC 26), Aspergillus niger (ATCC 9642) and Candida albicans (ATCC 10231). Antimicrobial activity (MIC) of the test compounds were determined by the broth microdilution method, with minor modifications as described below (Daouk et al., 1995; Hanel et al., 1988).

\section{Antitubercular activity}

The method used for antitubercular activity (Franzblau et al., 1998): Growth on Löwenstein Jensen (LJ) medium was suspended in sterile Middle brook $7 \mathrm{H} 9$ broth supplemented with $0.2 \%$ glycerol and 10\% OADC (oleatealbumin-dextrose-catalase) enrichment and a 1:20 dilution used as the inoculum for MABA. All manipulations were performed with appropriate safety hoods. $200 \mu \mathrm{L}$ of sterile deionized water was added to all outer perimeter wells of sterile 96 wells plate to minimize evaporation of medium in the test wells during incubation. The 96 wells plate received $100 \mu \mathrm{L}$ of the Middle brook $7 \mathrm{H} 9$ broth and serial dilution of compounds were made directly on the plate. The final drug concentrations tested were 0.01 to $32 \mu \mathrm{g} / \mathrm{mL}$. Plates were covered and sealed with parafilm and incubated at $37^{\circ} \mathrm{C}$ for five days. After this time, $25 \mu \mathrm{L}$ of freshly prepared 1:1 mixture of Alamar Blue reagent and 10\% tween 80 was added to the plate and incubated for $24 \mathrm{hrs}$. A blue color in the well was interpreted as no bacterial growth, and pink color was scored as growth. The minimum inhibitory concentration (MIC) is defined as the minimum concentration of the compound required to give complete inhibition of bacterial growth. The results were depicted in Table 1. 
Table 1: The Antitubercular activity of the synthesized compounds.

\begin{tabular}{cccccc}
\hline $\begin{array}{c}\text { Compound } \\
\text { code }\end{array}$ & $\begin{array}{c}\text { MIC } \\
(\mu \mathrm{g} / \mathbf{m L})\end{array}$ & $\begin{array}{c}\text { Compound } \\
\text { code }\end{array}$ & $\begin{array}{c}\text { MIC } \\
(\boldsymbol{\mu} \mathbf{g} / \mathbf{m L})\end{array}$ & $\begin{array}{c}\text { Compound } \\
\text { code }\end{array}$ & $\begin{array}{c}\text { MIC } \\
(\boldsymbol{\mu g} / \mathbf{m L})\end{array}$ \\
\hline AM1 & 12.5 & AM2g & 6.25 & AM5b & 50 \\
AM2 & 3.12 & AM3b & 12.5 & AM5c & 50 \\
AM3 & 3.25 & AM3c & 12.5 & AM5d & 25 \\
AM4 & 6.25 & AM3d & 3.25 & AM5e & 12.5 \\
AM5 & 6.25 & AM3e & 1.62 & AM5f & 12.5 \\
AM6 & 25 & AM3f & 3.25 & AM5g & 6.25 \\
AM1a & 50 & AM3g & 1.62 & AM6b & $>100$ \\
AM1b & $>100$ & AM4b & 12.5 & AM6c & $>100$ \\
AM1c & $>100$ & AM4c & 12.5 & AM6d & 100 \\
AM1d & 100 & AM2a & 25 & AM6e & 50 \\
AM1e & 50 & AM3a & 25 & AM6f & 100 \\
AM1f & 50 & AM4a & 50 & AM6g & 50 \\
AM1g & 50 & AM5a & 50 & INH & 1.6 \\
AM2b & 50 & AM6a & $>100$ & Pyrazinamide & 3.125 \\
AM2c & 50 & AM4d & 6.25 & Streptomycin & 6.25 \\
AM2d & 25 & AM4e & 3.25 & Ciprofloxacin & 3.125 \\
AM2e & 3.25 & AM4f & 6.25 & & \\
AM2f & 6.25 & AM4g & 3.25 & & \\
\hline
\end{tabular}

\section{Antimicrobial activity}

\section{Antibacterial activity}

The test compounds were dissolved in DMSO, and further diluted to 1:50 in RPMI-1640 medium and each resulting solution was used for a doubling dilution series. Microtiter plates were prepared to contain $100 \mu \mathrm{L}$ of undiluted extracts in the first well, followed by doubling dilutions of extracts from second well onwards. A standardized inoculum of each bacterial species was added to the respective dilution wells including the first well. The final concentrations of the compounds ranged from 100 to $0.8 \mu \mathrm{g} /$ $\mathrm{mL}$. For each test, there were sterility control wells containing test compound in RPMI-1640 broth plus DMSO and a growth control well containing bacterial suspension without test compound. The microtiter plates were incubated at $35 \pm 2{ }^{\circ} \mathrm{C}$ for 24 hours with their upper surface covered by sterile sealers. The lowest concentration of the test compound that did not show any visible growth was considered MIC of the compound for that bacterial species. All the experiments were carried out in triplicate. The results were depicted in Table 3.

\section{Antifungal activity}

Antifungal activity was evaluated by using agar well diffusion method against fungi Aspergillus niger-NCIM 652 and Candida albicans-NCIM 3102. $1 \mathrm{mg} / \mathrm{mL}$ stock solution of the selected compounds and Ketoconazole (antifungal standard) were prepared using methanol as a vehicle. Sabouraud's medium was used for fungal studies. $100 \mu \mathrm{L}$ of the inoculum was added to the sterilized agar medium, mixed, poured into sterile Petri plates and allowed to solidify. Wells of $6 \mathrm{~mm}$ diameter were made by using a borer and $100 \mu \mathrm{L}$ of the synthesized compounds, control and standards were transferred to them using micropipette. The Petri plate was incubated at $26^{\circ} \mathrm{C}$ for about $48 \mathrm{hrs}$ to determine the zone of inhibition. None of the compounds showed fungal activity.

\section{Drug-inhibitor combination studies (Rastogi et al., 1994)}

The $x / y$ quotient calculation method was used with slight modification to evaluate the combined drug (plus inhibitor) action. For this procedure, all the drugs and inhibitors were used at sub-lethal concentrations. The combined drug-inhibitor activity was assessed by calculating $x / y$ quotients as follows. The y value was the MIC obtained with the combination of drug-inhibitor by using the MABA method, whereas the $x$ value was the lowest MIC obtained at the same time with the drug or the inhibitor used alone. For combinations, an $x / y$ value of 1 indicated that there was no interaction between the two drugs, a quotient of $<0.5$ indicated enhanced drug action, whereas an $x / y$ quotient of $>2$ indicated the presence of antagonism between the drug and the inhibitor. The drugs or inhibitors were added at final concentrations 12.5, 6.12, $3.2,1.6,0.8,0.4,0.2,0.1 .0 .05$ and $0.025 \mu \mathrm{g} / \mathrm{mL}$ in $1: 1$ ratio. MIC of the drug-inhibitor combination is compared with the MIC of the drug. The results were depicted in Table 2.

Table 2: Combined drug-inhibitor activity against $M$. tuberculosis $\mathrm{H} 37 \mathrm{Rv}$ assessed by MABA method.

\begin{tabular}{ccc}
\hline S.No & Compound Code & $\begin{array}{c}\text { Enhancement of drug activities } \\
\text { (x/y coefficients })\end{array}$ \\
\hline 1 & $\mathrm{AM} 3 \mathrm{e}+\mathrm{INH}$ & $+++(0.031)$ \\
2 & $\mathrm{AM} 3 \mathrm{e}+\mathrm{RIF}$ & $+(0.50)$ \\
3 & $\mathrm{AM} 3 \mathrm{e}+\mathrm{CIP}$ & $+(0.125)$ \\
4 & $\mathrm{AM} 3 \mathrm{e}+\mathrm{STR}$ & $+(0.25)$ \\
\hline
\end{tabular}

INH - Isonicotinic acid hydrazide; RIF- Rifampicin; CIP - Ciprofloxacin, STR - Streptomycin.

\section{RESULTS AND DISCUSSION}

Our group has recently reported anti-TB activity for fluoxetine. This drug is a very important ingredient in antidepressant formulations currently used around the world. Hence, it cannot be considered for drug repurposing in anti-TB category because of its CNS activity and current clinical applications. As per the reported structure-activity relationship (SAR) data, we designed fluoxetine analogues with increased bulk on nitrogen to abolish CNS activity and obtain selective anti-TB agents (Andersen et al., 2009; Wenthur et al., 2014; Larsen et al., 2016).

The precursors of the target compounds, the aryloxyphenyl propanolamines (AM1b-6g), were obtained (Scheme 1) via synthesis of appropriate acetophenone mannich bases (AM1-6) followed by reduction (AM1a-6a) using sodium borohydride (Ali S et al., 2002; Ianni A et al., 2006). The resultant 3-(alkyl/arylalkyl-amino)-1-phenylpropan-1-ols (AM1a-AM6a), were then made to react with appropriate phenol using Mitsunobu reaction to obtain a total of 36 compounds (AM1b-AM6g) (Mitsunobu O, 1981). 
Kumar et al. / Journal of Applied Pharmaceutical Science 8 (08); 2018: 107-115

Table 3: Antibacterial activity of the synthesized compounds.

\begin{tabular}{|c|c|c|c|c|}
\hline \multirow{2}{*}{ Compound code } & \multicolumn{4}{|c|}{ Minimum Inhibitory Concentration (MIC90) in $\mu \mathrm{g} / \mathrm{mL}$} \\
\hline & S. aureus & B. subtilis & E. coli & P. vulgaris \\
\hline AM1 & 50 & 50 & $>100$ & $>100$ \\
\hline AM2 & 25 & 25 & 100 & 100 \\
\hline AM3 & 25 & 25 & 100 & 100 \\
\hline AM4 & 50 & 25 & $>100$ & $>100$ \\
\hline AM5 & 50 & 50 & $>100$ & $>100$ \\
\hline AM6 & 50 & 50 & $>100$ & $>100$ \\
\hline AM1a & $>100$ & 100 & $>100$ & $>100$ \\
\hline AM2a & 100 & 50 & $>100$ & $>100$ \\
\hline AM3a & $>100$ & 100 & $>100$ & $>100$ \\
\hline AM4a & 100 & 100 & $>100$ & $>100$ \\
\hline AM5a & 100 & 100 & $>100$ & $>100$ \\
\hline AM6a & $>100$ & $>100$ & $>100$ & $>100$ \\
\hline AM1b & 100 & $>100$ & $>100$ & $>100$ \\
\hline AM1c & 100 & 50 & $>100$ & $>100$ \\
\hline AM1d & 50 & 50 & $>100$ & 100 \\
\hline AM1e & 50 & 50 & $>100$ & 100 \\
\hline AM1f & 100 & 100 & $>100$ & 100 \\
\hline AM1g & 50 & 50 & $>100$ & $>100$ \\
\hline $\mathrm{AM} 2 \mathrm{~b}$ & 100 & $>100$ & $>100$ & $>100$ \\
\hline $\mathrm{AM} 2 \mathrm{c}$ & 50 & 50 & $>100$ & 100 \\
\hline $\mathrm{AM} 2 \mathrm{~d}$ & 50 & 50 & 100 & $>100$ \\
\hline AM2e & 25 & 25 & 50 & $>100$ \\
\hline $\mathrm{AM} 2 \mathrm{f}$ & 50 & 50 & 100 & 100 \\
\hline AM2g & 25 & 25 & 50 & $>100$ \\
\hline AM3b & 100 & 100 & $>100$ & 100 \\
\hline $\mathrm{AM} 3 \mathrm{c}$ & 50 & 50 & $>100$ & $>100$ \\
\hline AM3d & 25 & 25 & 100 & $>100$ \\
\hline AM3e & 25 & 25 & 100 & 100 \\
\hline AM3f & 50 & 50 & 100 & 100 \\
\hline AM3g & 25 & 25 & 100 & 100 \\
\hline $\mathrm{AM} 4 \mathrm{~b}$ & 100 & 100 & 100 & 100 \\
\hline $\mathrm{AM} 4 \mathrm{c}$ & 50 & 50 & 100 & 100 \\
\hline AM4d & 50 & 50 & 100 & 100 \\
\hline $\mathrm{AM} 4 \mathrm{e}$ & 25 & 25 & 100 & $>100$ \\
\hline AM4f & 50 & 50 & 100 & 100 \\
\hline $\mathrm{AM} 4 \mathrm{~g}$ & 50 & 50 & 100 & $>100$ \\
\hline AM5b & 100 & 100 & 100 & $>100$ \\
\hline $\mathrm{AM} 5 \mathrm{c}$ & 50 & 50 & 100 & 100 \\
\hline AM5d & 50 & 50 & $>100$ & 100 \\
\hline AM5e & 50 & 25 & $>100$ & 100 \\
\hline AM5f & 100 & 50 & 100 & 100 \\
\hline AM5g & 50 & 25 & $>100$ & 100 \\
\hline AM6b & $>100$ & $>100$ & $>100$ & $>100$ \\
\hline AM6c & 50 & 50 & 100 & 100 \\
\hline AM6d & 50 & 50 & 100 & 100 \\
\hline AM6e & 50 & 50 & 100 & 100 \\
\hline AM6f & 50 & 100 & 100 & 100 \\
\hline AM6g & 50 & 50 & 100 & 100 \\
\hline
\end{tabular}




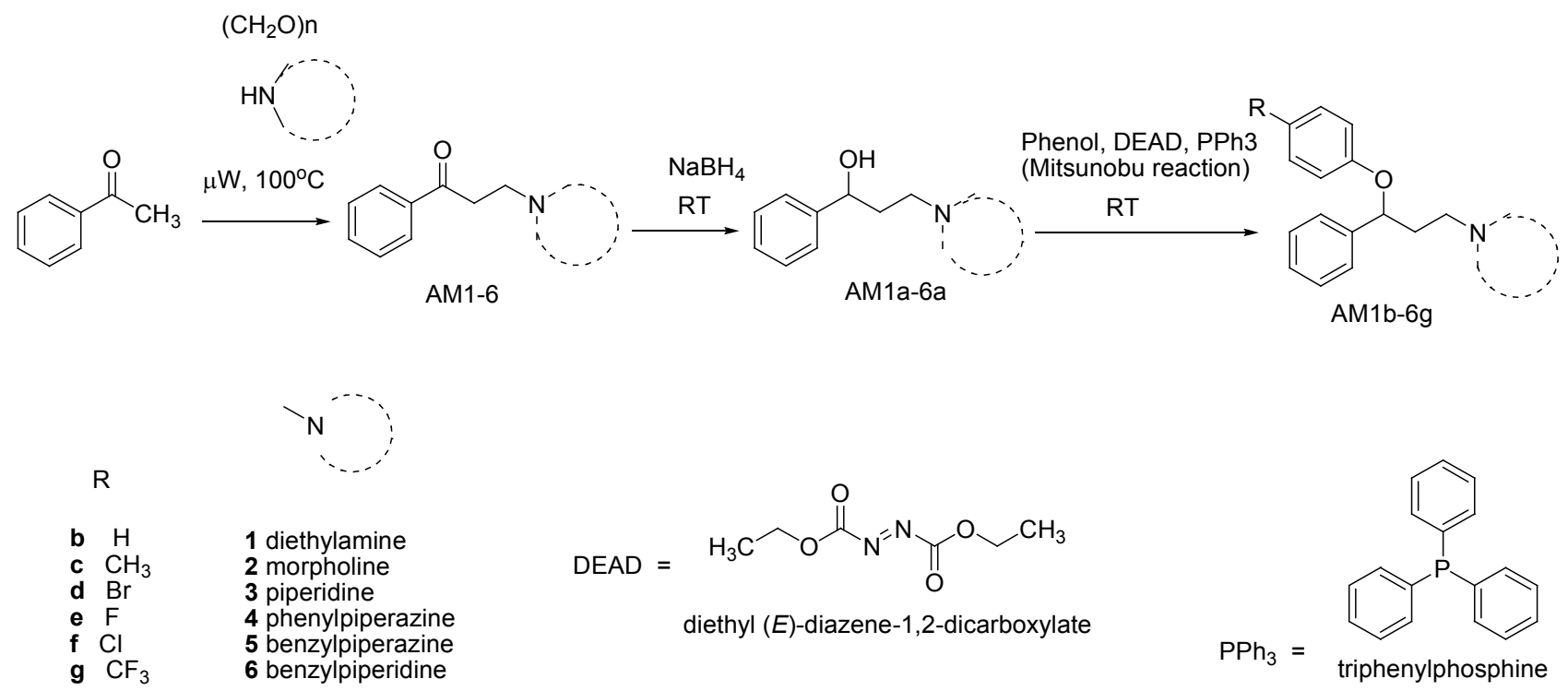

Scheme 1: Plan of synthesis for the target compounds.

The IR spectrum of the mannich bases (AM1a-AM6a) showed characteristic signals for ketone $(\mathrm{C}=\mathrm{O}$ str, 1670-1690 $\mathrm{cm}^{-1}$ ), amine (C-N str, 1280-1370), aromatic ring (-C=C-1610$1640 \mathrm{~cm}^{-1}$. C-H str, 2850-2980 $\left.\mathrm{cm}^{-1}\right)$. The ${ }^{1} \mathrm{HNMR}$ of AM1-6 showed signals for the aromatic ring in the range $\delta 7.16$ to 7.35 . Characteristic signals of the deshielded protons present on $\mathrm{C}-2$ and $\mathrm{C}-6$ of the benzene ring (ortho to $\mathrm{C}=\mathrm{O}$ group of the mannich base) at 7.85 to 7.98 as a doublet.

Further, the 3-(alkyl/arylalkyl-amino)-1-phenylpropan1-ols the precursors needed for fluoxetine analogue synthesis were obtained in quantitative yield. The compounds were obtained in the nearly pure state as viscous oils. The IR spectrum clearly showed the absence of signal for ketone $\left(1670-1690 \mathrm{~cm}^{-1}\right)$ and appearance of a new broad signal at $3240-3310 \mathrm{~cm}^{-1}$ indicating the formation of alcohol. The ${ }^{1} \mathrm{HNMR}$ also showed a $-\mathrm{C} \underline{\mathrm{H}}-\mathrm{OH}$ signal at $\delta 4.3$ to 5.0. The compounds were obtained as racemic mixtures, which were used as such for the next reaction. Formation of the target molecules (3-phenyl-3-(4-aryloxy)propyl)amines) were confirmed by the appearance of proton present on carbon bearing ether group at $\delta 4.80-5.25$ and disappearance of IR signal for -OH at $3200-3350 \mathrm{~cm}^{-1}$.

The synthesized compounds were screened for antimicrobial and antitubercular activity to obtain their selective toxicity profile. Among these (Table 1), AM3e showed four times more in vitro anti-TB activity (MIC $1.62 \mu \mathrm{g} / \mathrm{mL}$ ) than fluoxetine (MIC $6.25 \mu \mathrm{g} / \mathrm{mL}$ ) and is virtually free from antibacterial and antifungal activity (Table 3 ).

Among the others, the aryl ethers synthesized using 4F-phenol and 4-CF $-\mathrm{CF}_{3}$-phenol showed the highest potency. Change in the amine altered the activity in the order: morpholine $=$ piperidine $>$ phenylpiperazine $=$ benzylpiperazine $>$ diethylamine $=$ benzylpiperidine (Figure 1). The derivatives obtained from AM2 (morpholine), AM3 (piperidine), AM4 (phenylpiperazine) showed the highest potency. This study clearly showed the importance of electron withdrawing substituent at the $\mathrm{C}-4$ position of the phenoxy ring.

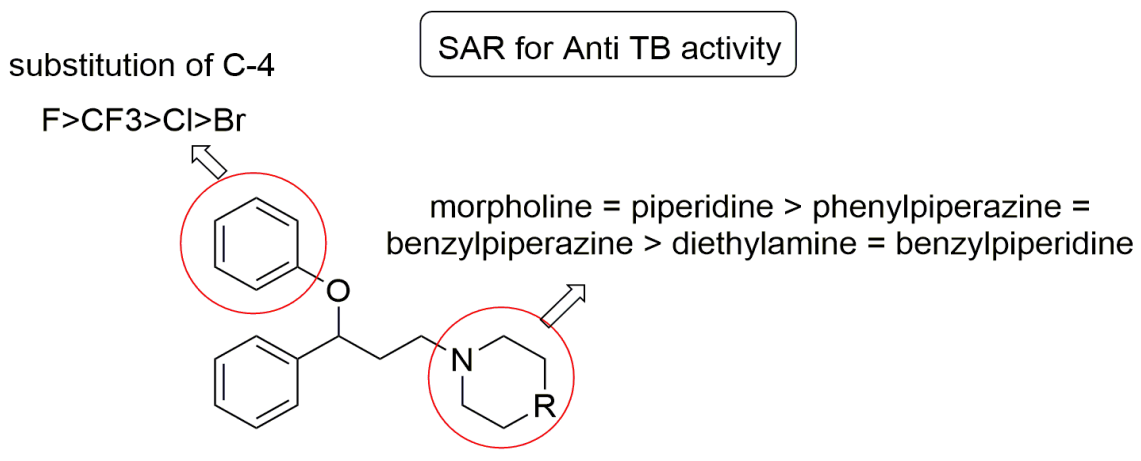

Fig. 1: SAR observed in anti-TB activity studies of the test compounds.

Among the synthesized compounds, mannich bases (AM1-6) showed feeble antibacterial activity against gram +ve test organisms with a MIC of $25-100 \mu \mathrm{g} / \mathrm{mL}$. Reduction of the keto group on mannich bases significantly reduced their antibacterial activity. The aryloxyphenyl-propylamine (AM1b-6g) derivatives also showed antimicrobial activity with a MIC of 25-100 $\mu \mathrm{g}$ / 
$\mathrm{mL}$. None of the synthesized compounds have shown antifungal activity below $100 \mu \mathrm{g} / \mathrm{mL}$. These observations ratified selective toxicity profile of the synthesized compounds.

Further, combined drug-inhibitor studies were performed to obtain mechanistic information. In these studies, AM3e showed synergism with INH, Rifampicin, Ciprofloxacin, and Streptomycin. This compound has also shown synergistic activity with the first line anti-TB drugs (Table 2) suggesting a new molecular target for this compound.

\section{CONCLUSION}

In our study, we identified potent and selective anti-TB activity in 1-(3-(4-fluorophenoxy)-3-phenylpropyl) piperidine (AM3e, MIC $1.6 \mu \mathrm{g} / \mathrm{mL}$ ) via optimizing the structure of fluoxetine. This compound has also shown synergism with first line anti-TB drugs. Further, our strategy could be used for efficient drug repurposing and to discover new leads for different diseases using known pharmacophores.

\section{ACKNOWLEDGMENTS}

We acknowledge the Science and Engineering Research Board (EMR/2014/000289). We also extend our sincere thanks to The Director, NMR Research Center, Andhra University for providing spectral data of our compound.

\section{CONFLICT OF INTEREST}

We have no conflict of interest.

\section{REFERENCES}

Ali S, Hosseein F, Farshid M, Naimi Jamal MR. Microwave Assisted Mannich Reaction of Terminal Alkynes on Alumina. Monatshefte fur Chemie, 2002; 133:199-204.

Andersen J, Kristensen AS, Bang-Andersen B, Strømgaard K. Recent advances in the understanding of the interaction of antidepressant drugs with serotonin and norepinephrine transporters. ChemComm, 2009; 25:3677-3692.

Juan Carlos P, Anandi M. Drug Resistance Mechanisms in Mycobacterium tuberculosis. Antibiotics, 2014; 85:317-340.

Daouk KD, Dagher MS, Sattout J. Antifungal Activity of the Essential Oil of Origanumsyriacum. L. J Food Prot, 1995; 58:1147-1149.

Franzblau SG, Witzig RS, McLaughlin JC, Torres P, Madico G, Hernandez A, Degnan MT, Cook MB, Quenzer VK, Ferguson RM and Gilman RH. Rapid, low-technology MIC determination with clinical Mycobacterium tuberculosis isolates by using the microplate Alamar Blue assay. J Clin.Microbiol, 1998; 36:362-366.

Hanel H, Raether W. A More Sophisticated Method of Determining the Fungicidal Effect of Water-Insoluble Preparations with a Cell Harvester, Using Miconazole as an Example. Mycoses, 1988; 31:148154.

Hari Babu Bolikala, Balaji Neduri V, Gottumukkala V Subbaraju, Purna Nagasree Kurre, Murali Krishna Kumar Muthyala. Synthesis, Screening and Docking Analysis of Hispolon analogs as Potential Antitubercular Agents. Bioorg. Med. Chem. Lett, 2017; 27:11-15.

Ianni A, Waldvogel SR. Reliable and Versatile Synthesis of 2-Aryl-Substituted Cinnamic Acid Esters. Synthesis, 2006; 13:2103-2112.

Kristiansen JE, Hendricks O, Delvin T, Butterworth TS,
Aagaard L, Christensen JB, Flores VC, Keyzer H. Reversal of resistance in microorganisms by help of non-antibiotics. J Antimicrob Chemother, 2007; 59:1271-1279.

Andreas M Larsen B, Plenge P, Andersen J, Eildal JNN, Kristensen AS, Bogeso KP, Gether U, Stromgaard K, Bang-Andersen B, Loland CJ. Structure-activity relationship studies of citalopram derivatives: examining substituents conferring selectivity for the allosteric site in the 5-HT transporter. British J Pharmacol, 2016; 173:925-936.

Larsen MA, Plenge P, Andersen J, Eildal JN, Kristensen AS, Bogeso KP, Gether U, Stromgaard K, Bang-Andersen B, Loland CJ, British J Pharmacol, 2016; 173:925-936.

Lass-Florl C, Dierich MP, Fuchs D, Semenitz E, Jenewein I, Ledochowski M. Antifungal properties of selective serotonin reuptake inhibitors against Aspergillus species in vitro. J Antimicrob Chemother, 2001; 48:775-779.

Mitsunobu O. The use of diethyl azodicarboxylate and triphenylphosphine in synthesis and transformation of natural products. Synthesis, 1981; 1:1-28.

Murali Krishna Kumar M, Madhavi K, Raghuveer Varma P, Risy Namratha J and Purna Nagasree K. Shape based virtual screening and discovery of potential antitubercular agents in non-antibiotics. Int J Drug Design and Disc, 2015; 6:1430-1434.

Mahalakshmi Naidu K, Srinivasarao S, Agnieszka N, Augustynowicz-Kopec Ewa, Murali Krishna Kumar M. Seeking potent anti-tubercular agents: Design, synthesis, anti-tubercular activity and docking study of various (triazoles/indole)-piperazin-1-yl/1,4-diazepan1-yl) benzo[d] isoxazole derivatives. Bioorg. Med. Chem. Lett, 2016; 26:2245-2250.

Martins M, Dastidar SG, Fanning S, Kristiansen JE, Molnar J, Pagès JM, Schelz Z, Spengler G, Viveiros M, Amaral L. Potential role of non-antibiotics (helper compounds) in the treatment of multidrugresistant Gram-negative infections: mechanisms for their direct and indirect activities. Int J Antimicrob Agents, 2008; 31:198-208.

Munoz-Bellido JL, Munoz-Criado S, Garc1 a-Rodrı guezJ A. Antimicrobial activity of psychotropic drugs Selective serotonin reuptake inhibitors. Int J Antimicrobial Agents, 2000; 14:177-180.

Silvestri R, Artico M, La Regina G, Di Pasquali A, De Martino G, D'Auria FD, Nencioni L, Palamara AT. Imidazole Analogues of Fluoxetine, a Novel Class of Anti-Candida Agents. J Med Chem, 2004; 47:3924-3926.

Rastogi N, Goh KS, Wright EL. Potential drug targets for Mycobacterium avium defined by radiometric drug-inhibitor combination techniques. Antimicrob Agents Chemother, 1994; 38:2287-2295.

Wenthur CJ, Bennett MR, Lindsley CW. Classics in Chemical Neuroscience: Fluoxetine (Prozac). ACS Chemical Neuroscience, 2014; 5:14-23.

Willyard C. The drug-resistant bacteria that pose the greatest health threats. Nature, 2017; 543:7643-7648.

WHO Global tuberculosis report. 2017. Available at http://www. who.int/.int/tb/publications/global_report/en [Accessed 1 Dec 2017].

WHO report. 2017. The world is running out of antibiotics, WHO report confirms, News release. Available at http://www.who.int/ mediacentre/news/releases/2017/running-out-antibiotics/en [Accessed 27 Feb 2018].

How to cite this article:

Kumar MMK, Madhavi K, Mohan T, Nagasree KP, Sangeeta GPV. Novel synthetic analogues of Fluoxetine as potent and selective anti-TB agents . J App Pharm Sci, 2018; 8(08): 107-115. 